\title{
The case for breast-conservation treatment rates to be a quality metric
}

The Editor

Current Oncology

10 March 2020

We read the article titled "Mastectomy versus breastconservation therapy: an examination of how individual, clinicopathologic, and physician factors influence decision-making" by Gu et al. ${ }^{1}$, recently published in Current Oncology, with great concern, and we wish to respond to the comments and conclusions made as a result of the authors' survey.

Dr. Gu and colleagues state that a paucity of Canadian data, specifically in their province of Saskatchewan, about the factors associated with the choice of surgical therapy for women with early-onset breast cancer served as the impetus for conducting their study. They affirm that interprovincial mastectomy rates vary greatly and report that, based on currently available Canadian data, Saskatchewan has a mastectomy rate of $63 \%$, with the national average being $38 \%$. Those data alone would identify Saskatchewan as a distant outlier in terms of contemporary Canadian practice patterns. Their retrospective survey of 276 women treated during the years 2007-2010 led to the conclusion that the complexity of surgical decision-making, predominantly tumour stage and individual patient beliefs, would explain the disparity in mastectomy rates. Hence, a high mastectomy rate should not be seen as a critical departure from best practice patterns, and patient choice was emphasized.

We find that their justification of allowing high mastectomy rates to persist because of patient choice is inconsistent with evidence-based best practice. The authors correctly state that, since 1991, [the U.S. National Cancer Institute/National Institutes of Health] guidelines encouraged the use of breast conservation treatment (ВСТ) over mastectomy in these patients because, at the time, the two were considered equivalent treatments from the standpoint of overall survival or local recurrence ${ }^{2}$. While it is true that historical foundational randomized controlled trials demonstrated equivalent survival with either surgical modality $^{3}$, increasing worldwide data from more than 500,000 women in the last decade demonstrate, however, that BCT is likely superior to mastectomy in both parameters ${ }^{4-6}$. A significant body of contemporary evidence supports BCT as the treatment of choice for women with early breast cancer $^{4,6}$. It is noteworthy that, with few exceptions, most of the references alluded to in the Gu et al. paper are more than 7 years old and do not include more recent data. Accumulated contemporary data clearly endorse the results of other Canadian provinces, such as Quebec, where a mastectomy rate of $25.3 \%$ is reported.

The Gu et al. retrospective study might be biased because of patient self-interest in medical decision-making. It was reported that, when the decision was patientdependent, a greater proportion elected to undergo mastectomy. Conversely, it is notable that when the decision was shared, or based on physician advice, women were more likely to choose BCT. To a great extent, that variability in individual patient choice was ascribed to "personal beliefs." Unfortunately, "personal belief" is not well defined, but "fear of recurrence" appeared to have a dominant role in the study. Such fear is not evidence-based, because recent studies demonstrate equivalent local control with both BCT and mastectomy ${ }^{2,5}$. Those data should be presented as part of counselling for informed consent to overcome personal beliefs and misconceptions that are inimical to best practice patterns. Ample resources are available to assist clinicians to increase the use of ВСТ, listed in detail as a "toolbox"?

The authors advise against the use of mastectomy and ВСт rates as indicators of quality of care and advocate a shift in attention toward patient choice in treatment. Unfortunately, their results-based on demographics, personal beliefs, and patient choice-should not supersede contemporary evidence on treatment outcomes. Given that current data support ВСТ over mastectomy, ВСТ should be recommended as the treatment of choice. The changes in data-driven best practice patterns have to be communicated clearly to patients such that the individual patient will garner the best outcome possible. There will be the occasional patient who, despite best efforts, might seek a second-best option. Perhaps, rather than defending the high mastectomy rates in Saskatchewan, physicians in the province might wish to evaluate how BCT rates could be increased to match those of other provinces in Canada within the same national health system, which already achieve best practice patterns.

M.P. Tan MBBS FRCS(Ed)

MammoCare

38 Irrawaddy Road, 06-21

329563 Singapore

jabezhopems@gmail.com

E. Silva MD PhD FACS

Department of Surgery

986345 University of Nebraska Medical Center

Omaha, Nebraska 68198-63445 U.S.A.

esilva@unmc.edu 


\section{CONFLICT OF INTEREST DISCLOSURES}

We have read and understood Current Oncology's policy on disclosing conflicts of interest, and we declare that we have none.

\section{REFERENCES}

1. Gu J, Delisle M, Engler-Stringer R, Groot G. Mastectomy versus breast-conservation therapy: an examination of how individual, clinicopathologic, and physician factors influence decision-making. Curr Oncol 2019;26:e522-34.

2. Fisher B, Anderson S, Bryant J, et al. Twenty-year follow-up of a randomised trial comparing mastectomy, lumpectomy, and lumpectomy plus irradiation for the treatment of invasive breast cancer. $N$ Engl J Med 2002;347:1233-41.

3. NIH Consensus Conference. Treatment of early-stage breast cancer. JAMA 1991;265:391-5.
4. Gentilini OD, Cardoso MJ, Poortmans P. Less is more. Breast conservation may be even better than mastectomy in early breast cancer patients. Breast 2017;35:32-3.

5. van der Heiden-van der Loo M, Siesling S, Wouters MWJM, van Dalen T, Rutgers EJT, Peeters PHM. The value of ipsilateral breast tumour recurrence as a quality indicator: hospital variation in the Netherlands. Ann Surg Oncol 2015;22(suppl 3): S522-8.

6. Tan MP, Silva E. Addressing the paradox of increasing mastectomy rates in an era of de-escalation of therapy: communication strategies. Breast 2018;38:136-43.

7. Landercasper J, Attai D, Atisha D et al. Toolbox to reduce lumpectomy reoperations and improve cosmetic outcome in breast cancer patients: the American Society of Breast Surgeons Consensus Conference.Ann Surg Oncol2015;22:3174-83. 